\title{
Can a decision aid enable informed decisions in neonatal nursery recruitment for a fragile $X$ newborn screening study?
}

\author{
Donald B. Bailey, Jr, PhD¹, Carla Bann, PhD'1, Ellen Bishop, MS'1, Sonia Guarda, MS², Leah Barnum, MA² \\ and Myra Roche, MS, CGC
}

Purpose: To determine whether a brochure based on principles of informed decision making improved attention to study materials or altered decisions made by parents invited to participate in a fragile $\mathrm{X}$ syndrome newborn screening study.

Methods: A total of 1,323 families were invited to participate in a newborn screening study to identify infants with fragile X syndrome as well as premutation carrier infants. Of these families, 716 received the original project brochure and 607 were given a new decision aid brochure.

Results: Families were more likely to look at the new decision aid and mothers were more likely to read it completely, but the proportion of mothers who read the entire decision aid was only $14 \%$. Families were more likely to rate the decision aid as very helpful.

\section{INTRODUCTION}

Recruiting research participants requires careful delineation of risks and benefits and should be accompanied by a rigorous informed consent process, but recruiting families to participate in neonatal research, especially for genetic testing and the return of results, poses special challenges. Ideally, parents should be informed about research during the prenatal period, allowing time to consider options, understand ramifications of study participation, and decide whether to participate. However, logistical and financial barriers in talking with parents during this period are substantial, often leading to in-hospital recruitment immediately before or shortly after birth—clearly a suboptimal time for thoughtful decisions.

\section{The newborn screening context}

The challenges of ethical recruitment are especially salient in newborn screening. In the United States, newborn screening is usually performed without informed consent on the assumption that the urgent need to treat identified conditions outweighs the ethical stipulation of consent. Parents are typically informed about newborn screening, however, and many states allow parents to opt out of screening for religious or moral reasons, although few parents do so. State decisions about which conditions merit screening are guided by recommendations from the Secretary's Advisory Committee on Heritable Disorders in Newborns and Children. ${ }^{1}$ Most parents accept the trade-off between the need for rapid action and the loss of
Consistent with informed decision making theory and research, participants receiving the decision aid brochure were less likely to agree to participate.

Conclusion: The decision aid increased attention to and perceived helpfulness of educational information about the study, but most families did not read it completely. The study suggests that even welldesigned study materials are not fully reviewed in the context of inhospital postpartum study recruitment and may need to be accompanied by a research recruiter to obtain informed consent.

Genet Med 2013:15(4):299-306

Key Words: fragile X; informed decision making; neonatal nursery; newborn screening; parent decisions

parental autonomy, ${ }^{2}$ although cross-country variations exist..$^{3-5}$ Some ethicists suggest that the possibility of whole-genome or whole-exome sequencing and the breadth of information potentially available will only heighten the debate, forcing mandatory screening to be reconsidered and strengthening the case for informed consent. ${ }^{6,7}$

Newborn screening pilot programs can be conducted by states without parental consent if the study meets institutional review board (IRB) criteria for minimal risk, protection of rights and welfare, and impracticability. ${ }^{8}$ However, preliminary studies gathering data needed before state-sponsored pilots must have a robust consent process. Such was the case with our fragile X newborn screening study, the project on which this article is based.

\section{The fragile $X$ newborn screening pilot study}

Fragile X syndrome (FXS) is the most common inherited form of intellectual disability. Because FXS lacks phenotypic specificity in the early years and developmental delays only gradually appear, most children are not identified until age 36 months or later. ${ }^{9}$ Delayed diagnosis has significant consequences for children (e.g., inability to participate in early intervention) and families (e.g., long diagnostic odysseys, costs in finding a correct diagnosis, and/or a second affected child)..$^{9-11}$

Newborn screening for FXS could benefit affected children and families but has not been included on state screening panels because it lacks a proven medical treatment that must begin early. In addition, screening relies on a DNA-based assay that

${ }^{1}$ Social, Statistical, and Environmental Sciences, RTI International, Research Triangle Park, North Carolina, USA; ${ }^{2}$ FPG Child Development Institute, University of North Carolina at Chapel Hill, Chapel Hill, North Carolina, USA; ${ }^{3}$ Department of Pediatrics, University of North Carolina at Chapel Hill, Chapel Hill, North Carolina, USA. Correspondence: Donald B. Bailey Jr (dbailey@rti.org) 
simultaneously identifies FMR1 premutation carriers. Although carrier identification might be useful to some families because it leads to identifying parental carrier status, carriers are also at increased risk for adult-onset conditions such as FX-primary ovarian insufficiency, FX-tremor ataxia syndrome, or other neuropsychological or emotional problems. ${ }^{12,13}$ Therefore, FX screening of neonates evokes difficult ethical considerations. The newborn's test results have uncertain value, suggesting an increased risk but not the certainty of disease. Most results indicate carrier status and predict the possibility of largely untreatable, adult-onset disorders for both baby and a parent. ${ }^{6,14-16}$ These realities dictate that parents play a meaningful role in deciding whether or not their child should participate in such a study. ${ }^{17-20}$

The study was designed to determine parents' interest in screening, their reasons for accepting or declining, family adaptation to learning about carrier status, and the early developmental progress of identified infants. Parents were recruited in the hospital shortly after their child's birth; those interested in hearing about the study were given a brochure and consent form by a bilingual research assistant (RA). The RA returned later to answer questions, provide clarification, and obtain consent. Screening results were relayed several weeks later by phone if positive and by letter if negative. Parents of screen-positive infants were offered genetic counseling, diagnostic confirmation, and parental carrier testing, and were invited to participate in a longitudinal study of infant development and family adaptation. An initial publication reported an acceptance rate of $63 \%$, which remained relatively constant throughout the study, with black families significantly less likely to participate as compared with other parents. ${ }^{21}$

\section{Pilot study educational materials}

A study brochure was developed in accordance with IRB regulations, but during the course of the study the authors became concerned that its emphasis on FXS may have prevented parents from fully understanding that the most likely screen-positive result would identify carriers. In an informal preassessment, fewer than half of the parents reported looking at it. A possible explanation for the lower participation of black families could have been that the original brochure did not state that FXS affects all ethnic/minority groups.

To address these concerns, a new brochure was designed to be more visually appealing, to include photographs of families from multiple racial groups, and to place more emphasis on carrier identification. The design incorporated well-accepted principles of informed decision making (IDM) to create a "decision aid" that supported families in weighing various factors to help them arrive at a decision consistent with their values and preferences. $^{22}$

IDM is a method recommended in health-care situations in which patients must make a decision for which there is no objective right or wrong answer. A decision is considered effective when it is consistent with the person's own values and preferences. ${ }^{23}$ IDM is usually supported by decision aids-print or audiovisual materials describing the decision to be made and providing strategies for weighing choices and personal values. ${ }^{24}$ Reviews of decision aids suggest that they improve knowledge and inform decisions. ${ }^{25,26}$ For example, a recent study of young women with early-stage breast cancer found that, as compared with usual care, women who received the decision aid knew more about their options, were more certain about their decisions, and had less decisional regret. ${ }^{27}$ Ironically, the principles of IDM are rarely incorporated in the consent process. A review of consent documents used in 139 clinical trials concluded that most failed to meet international standards for supporting informed decisions ${ }^{28}$ and, with only a few exceptions, ${ }^{29}$ the application of IDM to the consent process has not been studied.

We recently described our decision aid, provided details about how it was developed, and reported initial evidence of usefulness. ${ }^{30}$ The decision aid, designed in a brochure format, received high scores on informational content, guidance, and values from an independent panel of experts using the International Patient Decision Aids Standards Collaboration checklist. ${ }^{31}$ In a simulation study, pregnant women or new mothers rated the aid high in quality and trustworthiness. They scored an average of $91.1 \%$ correct on a knowledge test after reading it once (in an average of $6.4 \mathrm{~min}$ ). When asked to make a hypothetical decision, $61.9 \%$ would choose to have their child screened; of note, minority women were not significantly less likely to trust the aid or agree to screening.

\section{Research questions}

The ultimate test of the usefulness of a decision aid can only be determined in an actual decisional context, reported here to answer five questions:

- Was the decision aid brochure more likely to be looked at than the original brochure?

The decision aid was more colorful than the original brochure, with numerous photographs of parents and infants. We hypothesized that it would increase the number of families in which at least one person looked at it.

- Was the decision aid more likely to be read completely by mothers than the original brochure?

Because of the visual appeal and revised format, we hypothesized that mothers would be more likely to read it completely than those receiving the original brochure.

- Did parents rate the decision aid as more helpful than the original brochure in deciding whether to participate?

Because the decision aid was developed with techniques supporting IDM, we hypothesized that it would receive higher ratings of perceived helpfulness than the original brochure.

- Did the decision aid alter decisions about study participation? 
Two reviews of decision aids found that they often result in lower uptake rates. ${ }^{25,26}$ Accordingly, we hypothesized that, in families in which the mother read the entire brochure, there would be a lower rate of participation in those who read the decision aid as compared with the original brochure.

- To what extent were maternal education and race/ethnicity associated with variation in the answers to the first four questions?

We hypothesized that the decision aid's pictorial depiction of families from multiple races would lead to an increase in minority mothers who read it and greater cross-ethnic similarity in study participation.

\section{MATERIALS AND METHODS}

We used a baseline-intervention design to evaluate the effects of the decision aid. The original brochure was used in the recruitment process for 7 months, followed by a 6-month period using the decision aid.

\section{Subjects}

A total of 1,323 families who had given birth in a universitybased hospital agreed to hear about the study from an RA, giving them the opportunity to read the recruitment materials; of these, 716 received the original brochure and 607 received the decision aid. Their demographic characteristics are displayed in Table 1 . The mothers had a mean age of 28.7 years and represented a diverse range of ethnicities: $45.7 \%$ white, $14.8 \%$ black, $33.9 \%$ Hispanic, and 5.7\% other. Approximately 26\% had less than a high school education, $18 \%$ had a high school or GED diploma, $15 \%$ some college or community college education, $18 \%$ a college degree, and $22 \%$ a post-baccalaureate degree.

\section{Procedures and instruments}

As detailed in the original report, ${ }^{21}$ all mothers aged 15 years or older (excluding those with medically ill infants, infants given up for adoption, and mothers who spoke neither English nor Spanish) were approached by a bilingual RA in the postpartum unit and asked if they were interested in hearing about a research study. If interested, they were given a brochure and consent form (English and Spanish versions were available for the original brochure, the decision aid, and the consent form) and had the opportunity over the next few hours to discuss the project with the RA. For a 7-month period, families were given the original brochure, followed by a 6-month period with the decision aid. Otherwise, all recruitment procedures remained the same throughout the course of the study.

Families decided whether they wanted to have their children screened. Once they had decided, the RA asked whether they would answer a few questions about demographic characteristics and three brief questions about the brochure. Those who verbally assented (almost all parents) provided this information. The university IRB approved the survey questions and did not ask for documentation of consent. The following questions were asked:
- Have you or anyone in your family looked at this brochure about the study? Mothers indicated whether they, the father, or another family member had looked at it.

- Which of the following best describes how much you (the mother) were able to read: none; looked at the cover; quickly glanced through it but did not read it all; or read the whole thing?

- How helpful was the brochure in deciding whether the study is right for your child: not at all; somewhat; or very?

\section{Data analyses}

Demographic characteristics of participants receiving the decision aid and the original brochure were compared using $\chi^{2}$ tests. We conducted logistic regression models to examine the impact of brochure type on whether anyone looked at it, whether mothers read the whole brochure, and whether family members who looked at it considered it "very helpful." Regression models controlled for marital status, education, mother's race/ethnicity and age, and whether Spanish was her primary language. In addition, we tested for interactions between brochure type and race/ ethnicity for each racial/ethnic group. Finally, we conducted similar logistic regression models to compare participation rates among parents based on brochure type and demographics, as well as whether the mother had read the whole brochure.

\section{RESULTS}

Demographic characteristics of participants by brochure type are shown in Table 1. Participants receiving the decision aid did not differ significantly from those receiving the original brochure on marital status, mother's age, education, race/ethnicity, or primary language.

\section{Use and perceptions of brochures}

Families receiving the decision aid were significantly more likely to report that at least one family member looked at it than those receiving the original brochure $(P=0.02$; Table 2$)$. Fortyfour percent of families receiving the decision aid looked at it as compared with $39 \%$ of families receiving the original. Married parents were more likely than single parents $(P=0.045)$ and Spanish speakers were less likely than non-Spanish speakers $(P=0.017)$ to look at either brochure.

Mothers receiving the decision aid were more likely to read the whole brochure, controlling for demographics $(P=0.043)$. Fourteen percent read the new brochure completely as compared with $11 \%$ with the original brochure. Across both brochures, mothers who spoke Spanish were less likely to have read the whole brochure $(P<0.001)$. Testing interaction effects revealed that the impact of the new brochure was greater among Hispanic mothers than white mothers (odds ratio (95\% confidence interval $)=1.30(1.06,1.61), P=0.014)$. As shown in Figure 1, the percentage of Hispanic mothers reading the entire brochure increased from $6 \%$ for the original brochure to $14 \%$ for the decision aid.

Families were more likely to rate the decision aid as very helpful $(P=0.015$; Table 2$)$ than the original brochure. Although 
Table 1 Demographic characteristics, use of brochure, and study participation by brochure type

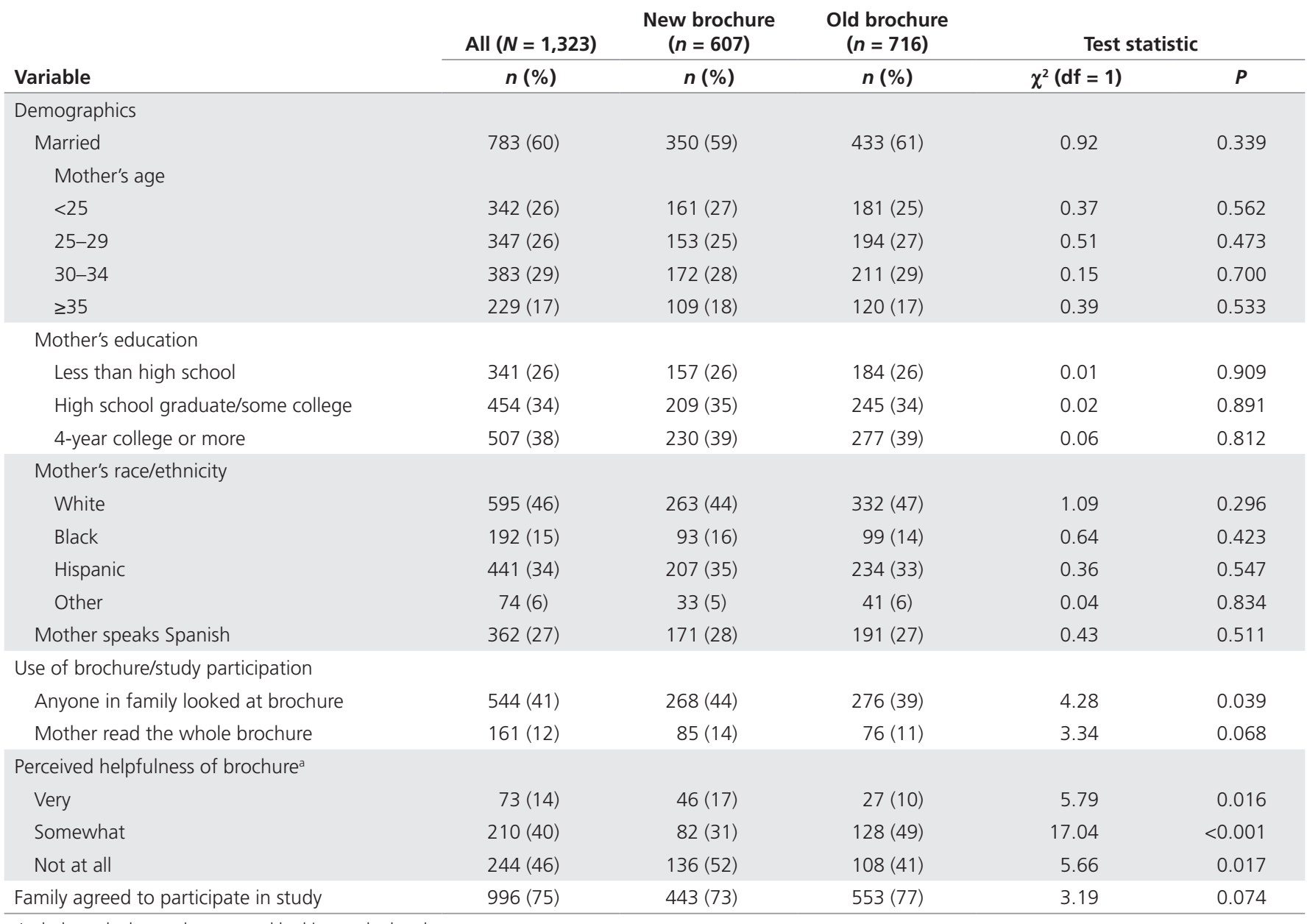

ancludes only those who reported looking at the brochure.

not statistically significant at $P<0.05$, families in which the mother had less than a high school education (vs. 4-year college or more) and those who were black (vs. white) tended to be more likely to find the decision aid very helpful $(P=0.051$ and $P=0.056$, respectively). A significant interaction suggests that the effect of the new brochure is greater for black vs. white mothers (odds ratio $(95 \%$ confidence interval $)=1.37(1.04$, 1.81), $P=0.025)$. Among black families, $77 \%$ described the decision aid format as very helpful vs. only $44 \%$ for the original brochure; in comparison, these values were $43 \%$ vs. $39 \%$ for white families (Figure 2).

\section{Agreement to participate in the study}

Controlling for demographics, participants receiving the decision aid were less likely to participate in the study than those receiving the original brochure $(P=0.028$; Table 3$)$. Seventythree percent of all families who received the decision aid agreed as compared with $77 \%$ who received the original brochure. (These percentages are higher than the $63 \%$ reported in Skinner et al. ${ }^{21}$ because our numbers are of those families who agreed to consider study participation (and thus had the opportunity to read the brochure) whereas Skinner et al. ${ }^{21}$ reported the percentage of all families approached, some of whom were not interested in any research and so were not given a brochure.) Families in which the mother was black ( $P$ $<0.001)$ or other race (vs. white) $(P=0.009)$ were less likely to participate. Although not statistically significant at $P<0.05$, the interaction between brochure type and reading the whole brochure suggests that the decision aid had a greater impact on study participation when the mother had read the entire brochure $(P=0.057)$. Among those receiving the original brochure, $72 \%$ of those who read all of it agreed to participate as compared with $78 \%$ of those who did not read it. However, only $54 \%$ of those who read the entire decision aid agreed to participate in the study as compared with $76 \%$ among those who did not read the entire decision aid.

\section{DISCUSSION}

Our primary goal was to test whether the use of IDM principles to design a decision aid about a study involving genetic testing and the return of results would increase parents' attention to and perceived usefulness of recruitment materials. In a simulation study ${ }^{30}$ we had demonstrated that the decision aid (i) met established criteria for IDM, (ii) resulted 
Table 2 Logistic regression models of use and perceived helpfulness of the brochure

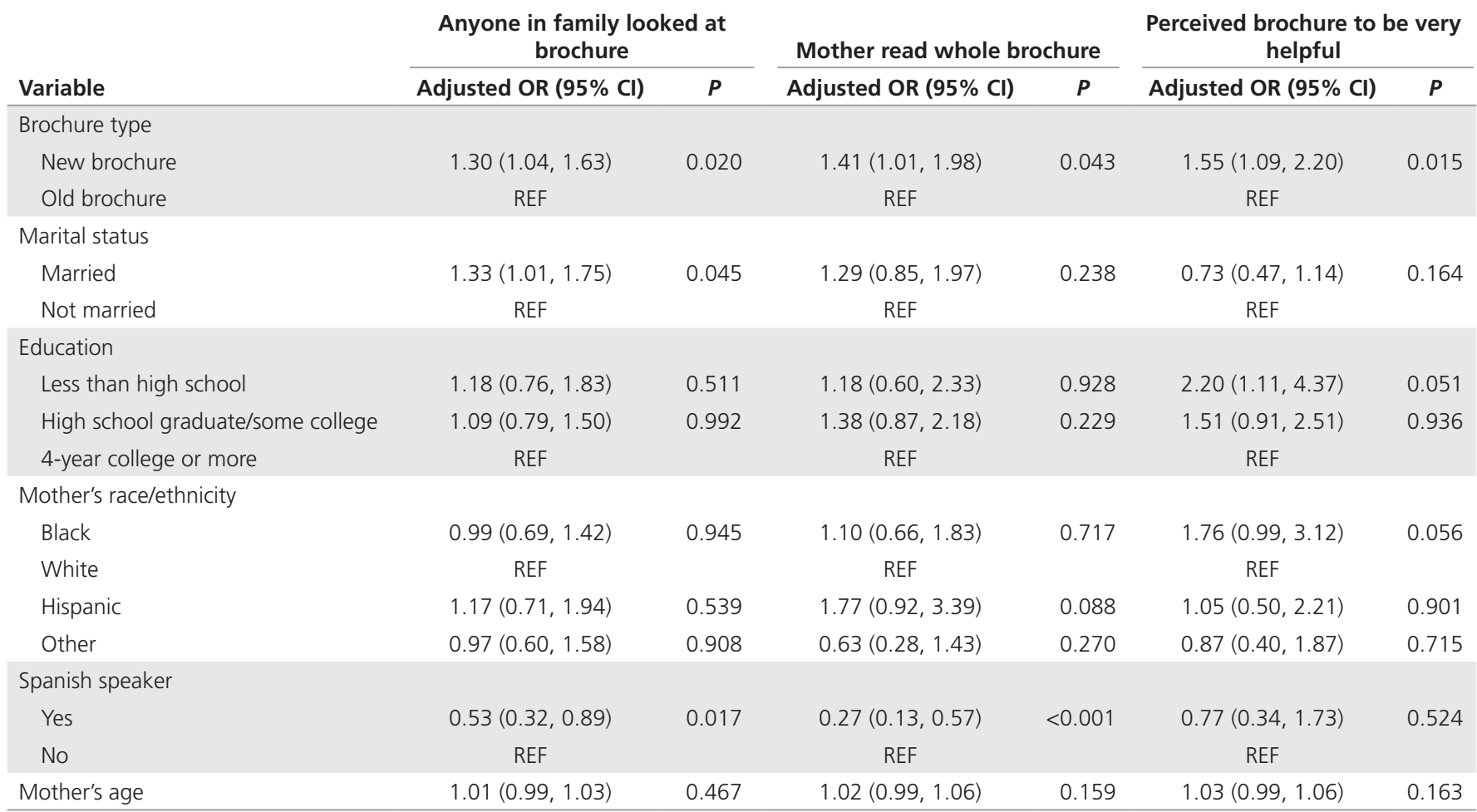

Odds ratios are adjusted for brochure type, marital status, education, race/ethnicity, Spanish language, and age.

$\mathrm{Cl}$, confidence interval; OR, odds ratio; REF, reference category.

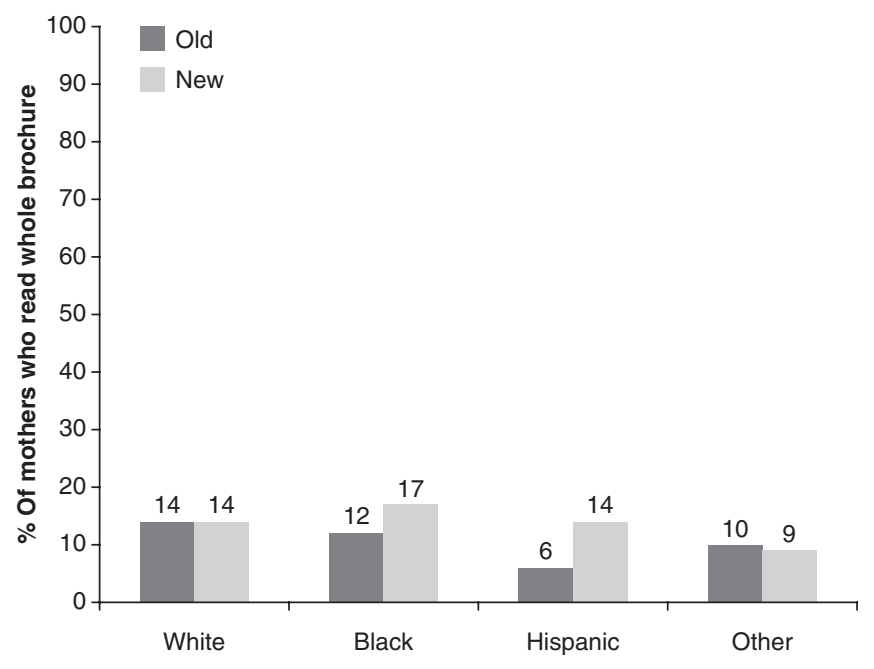

Figure 1 Percentage of mothers reading the whole brochure by race/ ethnicity.

in a high degree of factual knowledge both about the study and about what families might learn from FX screening, and (iii) was rated highly in both quality and usefulness by a small $(N=118)$ group of pregnant women and recent mothers. The simulated population differed from the recruitment population by several key factors, including higher education level and better English fluency, not being hospitalized nor having recently given birth, and the hypothetical nature of their decisions.

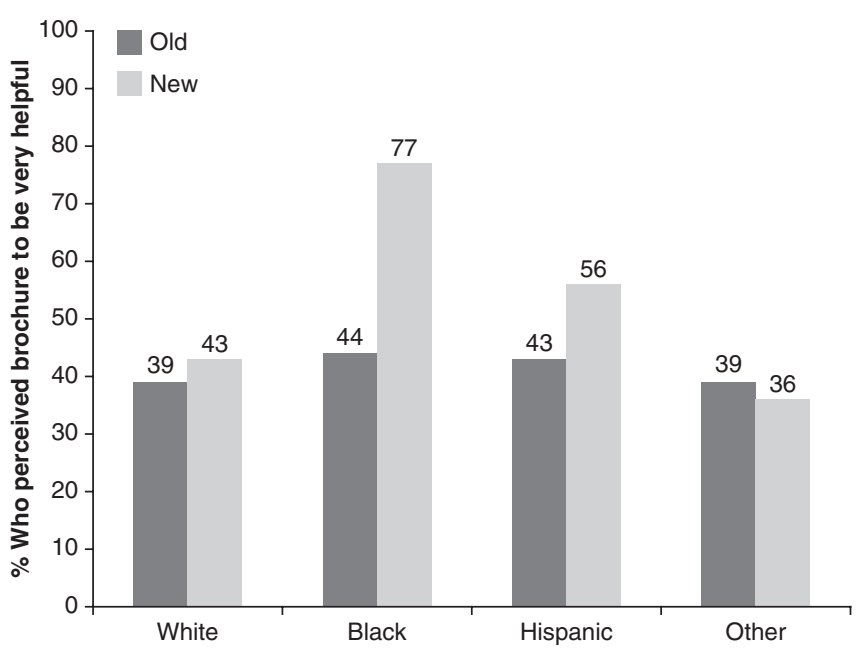

Figure 2 Percentage of families perceiving new and old brochures to be very helpful by race/ethnicity.

The effect of the decision aid was then tested using a comparison study implemented in the FX pilot screening environment with a more diverse population. The women had just given birth and had to decide about study participation in a short period of time, before the phlebotomist obtained the baby's blood for the state screening program. Increasing the uptake of study participation was not our goal. Instead, we sought to maximize the likelihood of parents' making a fully informed decision, one that more closely aligned with their personal values and preferences. 
Table 3 Logistic regression models of agreement to participate in the study

\begin{tabular}{|c|c|c|c|}
\hline \multirow[b]{2}{*}{ Variable } & \multicolumn{3}{|c|}{ Family agreed to participate in study } \\
\hline & $n(\%)$ & $\begin{array}{l}\text { Adjusted OR } \\
(95 \% \mathrm{Cl})\end{array}$ & $P$ \\
\hline \multicolumn{4}{|l|}{ Brochure type } \\
\hline New brochure & $443(73)$ & $0.81(0.68,0.98)$ & 0.028 \\
\hline Old brochure & $553(77)$ & REF & \\
\hline \multicolumn{4}{|l|}{ Marital status } \\
\hline Married & $614(78)$ & $1.04(0.76,1.43)$ & 0.812 \\
\hline Not married & $382(74)$ & REF & \\
\hline \multicolumn{4}{|l|}{ Education } \\
\hline $\begin{array}{l}\text { Less than } \\
\text { high school }\end{array}$ & $256(75)$ & $0.71(0.42,1.18)$ & 0.345 \\
\hline $\begin{array}{l}\text { High school } \\
\text { graduate/some college }\end{array}$ & $332(73)$ & $0.75(0.51,1.10)$ & 0.465 \\
\hline 4-year college or more & $408(80)$ & REF & \\
\hline \multicolumn{4}{|l|}{ Mother's race/ethnicity } \\
\hline Black & $121(63)$ & $0.39(0.26,0.59)$ & $<0.001$ \\
\hline White & $489(82)$ & REF & \\
\hline Hispanic & $334(76)$ & $0.78(0.43,1.44)$ & 0.427 \\
\hline Other & $52(70)$ & $0.48(0.28,0.83)$ & 0.009 \\
\hline \multicolumn{4}{|l|}{ Spanish speaker } \\
\hline Yes & $275(76)$ & $1.04(0.56,1.93)$ & 0.896 \\
\hline No & $721(77)$ & REF & \\
\hline Mother's age & - & $0.98(0.96,1.01)$ & 0.183 \\
\hline \multicolumn{4}{|l|}{ Read the whole brochure } \\
\hline Yes & $101(63)$ & $0.68(0.57,0.82)$ & $<0.001$ \\
\hline No & $888(77)$ & REF & \\
\hline $\begin{array}{l}\text { Period } \times \text { read } \\
\text { whole brochure }\end{array}$ & & $0.84(0.70,1.01)$ & 0.057 \\
\hline $\begin{array}{l}\text { New: read whole } \\
\text { brochure }\end{array}$ & $46(54)$ & & \\
\hline $\begin{array}{l}\text { New: did not read } \\
\text { whole brochure }\end{array}$ & $396(76)$ & & \\
\hline $\begin{array}{l}\text { Old: read whole } \\
\text { brochure }\end{array}$ & $55(72)$ & & \\
\hline $\begin{array}{l}\text { Old: did not read } \\
\text { whole brochure }\end{array}$ & $492(78)$ & & \\
\hline
\end{tabular}

Percentages represent the proportion of families with the characteristic who agreed to participate in the study (e.g., $78 \%$ of those who were married agreed to participate). Odds ratios are adjusted for brochure type, marital status, education, race/ethnicity, Spanish language, age, reading the brochure, and the interaction between brochure type and reading the brochure.

$\mathrm{Cl}$, confidence interval; OR, odds ratio; REF, reference category.

This goal was partially achieved. Consistent with our original hypotheses, when compared with the participants given the original brochure, those given the decision aid were more likely to report that someone looked at it; mothers were more likely to have read the entire brochure and they were more likely to perceive it as "very helpful." Increased attention to the brochure was likely influenced by differences in design and layout. The original brochure was a pink and blue trifold with no photographs, printed on card stock paper. The decision aid was a colorful eight-page "magazine-type" format with photographs on each page, printed on semi-gloss paper. Ratings of "helpfulness" were likely influenced by the attention given to IDM principles in the decision aid, which included two pages devoted to "things to consider when making your decision," and a set of "questions to help you decide," followed by the following concluding statement: "If you answered Yes to most of the questions above, maybe you are ready to have your newborn screened. If you answered No to most, maybe this is not the right decision for you."

Race/ethnicity played a role in these ratings. The decision aid had a greater impact on Hispanic mothers reading the whole brochure as compared with white mothers, and the increase in perceived helpfulness was greater among black mothers than among white mothers. The photographs depicting families of different ethnicities may have influenced these findings. Also, the decision aid mentioned that FXS affects all ethnic and racial groups, a fact not mentioned in the original brochure.

Of note, despite the wide range of formal education, education was not significantly associated with these or any other outcome, either as a main effect or an interaction effect. This is somewhat surprising, because a readability analysis showed that it was written at a 9th grade level, primarily due to numerous three- and four-syllable words that could not be removed (e.g., family, carrier, genetics, and development). It is possible that our multiple editorial reviews, pilot testing, attention to layout and design, and plain language reviews helped maximize readability, and the fact that many three-syllable words in the pamphlet (with the exception of "carrier" and "genetics") are common.

Enthusiasm about the statistically significant improvements seen with the decision aid, however, is tempered by the fact that fewer than half (44\%) of the families reported that anyone looked at the decision aid at all. Fewer than $30 \%$ of the mothers looked at it, and of those, fewer than half read the entire brochure. In other words, of all of the mothers given the decision aid pamphlet, only $~ 14 \%$ read it completely. Although this is a slight improvement over the $11 \%$ who read the original brochure completely, this percentage does not come close to approaching the goal of providing informational materials that are read by most mothers. It can be argued that the timing and setting played a substantial role in creating a suboptimal environment for informed consent. Parent decisions about participation in research naturally take a back seat to other demands and priorities faced by families during this period.

Still, there is evidence that the decision aid had some influence on decisions about study participation. Across the entire sample, the decision aid resulted in a slight but statistically insignificant reduction in participation rates $(77.2 \%$ with the original brochure and $73.0 \%$ with the decision aid). However, when mothers read the entire brochure, there was a substantial reduction in participation from $72 \%$ with the original brochure to $54 \%$ with the decision aid. This difference did not quite reach statistical significance, most likely because of the small sample size of women who read the whole brochure. We had hypothesized that there would be some decrease based on 
literature showing that decision aids generally result in reduced acceptance of treatment or screening options. ${ }^{25,26}$ Theoretically, placing the information about screening into a broader context of personal values enables parents to identify choices inconsistent with their values and thus reject them. ${ }^{32}$ The magnitude of the reduction in study participation was surprising even though previous research has also reported significant drops in acceptance rates. For example, a study investigating the use of a decision aid about bowel cancer screening showed that the decision aid was associated with higher knowledge and greater confidence in decisions but reduced participation in fecal occult blood testing from 75 to $59 \% .{ }^{33}$ Our decision aid presented a balance of reasons to participate or not, giving explicit permission for parents to decline. It is also possible that the decision aid, when fully read, helped mothers realize that the information that could be learned from this screening was qualitatively different from that obtained from traditional newborn screening. The lack of specific interventions for newborns with a premutation, in combination with frank statements that FXS has "no cure," could have influenced mothers to conclude that screening was not urgent and that the value of the information gained would be uncertain and potentially worrisome. It is also possible that mothers who read the entire decision aid began to appreciate the complexities involved in making this decision and opted out because of the short time frame for deciding.

\section{Conclusion}

Many strategies could be used to improve the consent process, only one of which is improving the clarity and usefulness of informational materials. ${ }^{34,35}$ In this study, we show that a carefully designed set of informational materials can improve parents' attention to them and, for those who do read them, the IDM format can result in lower rates of participation, an indication that the decision-making process has been influenced. The fact that only $14 \%$ of the mothers read the entire decision aid brochure is sobering but should be tempered by the recognition that parents use multiple sources of information on which to base decisions. The RAs for this project spent considerable time discussing the study with families, and we believe that before signing the consent form, most families understood the study, at least in general terms, including the broader implications of their decision to participate. We do not have independent confirmation of this, however, and were not able to study the relative impact of the RAs' interactions with families as compared with the impact of the pamphlet on families' understandings.

This study raises fundamental questions about whether written materials alone, even when well designed, will be sufficient to obtain the degree of informed consent considered acceptable for research participation during this period, especially for decisions that require comprehending complex information. Consent for research increasingly includes decisions about a wide range of genomic testing. ${ }^{36}$ Although it could be argued that it is unrealistic to expect parents to be fully educated about genetics and the potential ramifications of genetic testing, researchers are obligated to use materials and procedures that lead to informed consent. Written materials likely will need to be viewed as a supplement to important personal interactions with a research recruiter or health-care provider, but the timing and cost of such interactions are substantial, and creative strategies are needed to minimize these costs. As one example, the educational component of a genetic counseling session has been examined to assess whether use of a "pre-visit" website to provide patients with a question prompt sheet could encourage more active and meaningful participation. ${ }^{37}$ However, obtaining informed consent under the constraints posed by both the timing and context of newborn screening will grow even more challenging with the adoption of NextGen technologies, ${ }^{38}$ heightening the need to develop and test effective supplemental educational methods to help individuals make decisions consistent with their values and beliefs.

\section{ACKNOWLEDGMENTS}

Primary support for this study was provided by the National Newborn Screening and Genetics Resource Center, through a cooperative agreement between the Maternal and Child Health Bureau, Genetic Services Branch, and the University of Texas Health Science Center at San Antonio, Department of Pediatrics, Health Resource and Services Administration grant no. U32-MC00148. Partial support was also provided by the Eunice Kennedy Shriver National Institute for Child Health and Human Development (P30 HD003110-S1), the Ethical, Legal, and Social Implications Research Program/National Human Genome Research Institute (5P5OHG004488), and the Centers for Disease Control and Prevention in conjunction with the Association for Prevention Teaching and Research (Cooperative Agreement no. U50/CCU300860, Project TS-1470).

\section{DISCLOSURE}

The authors declare no conflict of interest.

\section{REFERENCES}

1. Calonge N, Green NS, Rinaldo P, et al.; Advisory Committee on Heritable Disorders in Newborns and Children. Committee report: Method for evaluating conditions nominated for population-based screening of newborns and children. Genet Med 2010;12:153-159.

2. Hasegawa LE, Fergus KA, Ojeda N, Au SM. Parental attitudes toward ethical and social issues surrounding the expansion of newborn screening using new technologies. Public Health Genomics 2011;14:298-306.

3. Detmar S, Hosli E, Dijkstra N, Nijsingh N, Rijnders M, Verweij M. Information and informed consent for neonatal screening: opinions and preferences of parents. Birth 2007;34:238-244.

4. Moody L, Choudhry K. Parental views on informed consent for expanded newborn screening. Health Expect 2011; e-pub ahead of print 12 August 2011

5. Quinlivan JA, Suriadi C. Attitudes of new mothers towards genetics and newborn screening. J Psychosom Obstet Gynaecol 2006;27:67-72.

6. Goldenberg AJ, Sharp RR. The ethical hazards and programmatic challenges of genomic newborn screening. JAMA 2012;307:461-462.

7. Ross LF. Mandatory versus voluntary consent for newborn screening? Kennedy Inst Ethics J 2010;20:299-328.

8. Tarini BA, Burke W, Scott CR, Wilfond BS. Waiving informed consent in newborn screening research: balancing social value and respect. Am J Med Genet C Semin Med Genet 2008;148C:23-30. 
9. Bailey DB Jr, Raspa M, Bishop E, Holiday D. No change in the age of diagnosis for fragile $x$ syndrome: findings from a national parent survey. Pediatrics 2009;124:527-533.

10. Bailey DB, Skinner D, Hatton D, Roberts J. Family experiences and factors associated with the diagnosis of fragile X syndrome. J Dev Behav Pediatr 2000;21:315-321.

11. Bailey DB Jr, Skinner D, Sparkman KL. Discovering fragile $X$ syndrome: family experiences and perceptions. Pediatrics 2003;111:407-416.

12. Bailey DB Jr, Raspa M, Olmsted M, Holiday DB. Co-occurring conditions associated with FMR1 gene variations: findings from a national parent survey. Am J Med Genet A 2008;146A:2060-2069.

13. Pirozzi F, Tabolacci E, Neri G. The FRAXopathies: definition, overview, and update. Am J Med Genet A 2011;155A:1803-1816.

14. Bailey DB Jr, Skinner D, Davis AM, Whitmarsh I, Powell C. Ethical, legal, and social concerns about expanded newborn screening: fragile $X$ syndrome as a prototype for emerging issues. Pediatrics 2008;121:e693-e704.

15. Caga-anan EC, Smith L, Sharp RR, Lantos JD. Testing children for adult-onset genetic diseases. Pediatrics 2012;129:163-167.

16. Evans JP, Burke W, Khoury M. The rules remain the same for genomic medicine: the case against "reverse genetic exceptionalism". Genet Med 2010;12:342-343.

17. Archibald AD, Jaques AM, Wake S, Collins VR, Cohen J, Metcalfe SA. "It's something I need to consider": decisions about carrier screening for fragile $X$ syndrome in a population of non-pregnant women. Am J Med Genet $A$ 2009;149A:2731-2738.

18. Hoge SK, Appelbaum PS. Ethics and neuropsychiatric genetics: a review of major issues. Int J Neuropsychopharmacol 2012;25:1-11.

19. Ormond KE, Iris M, Banuvar S, Minogue J, Annas GJ, Elias S. What do patients prefer: informed consent models for genetic carrier testing. J Genet Couns 2007;16:539-550.

20. Wilfond B, Ross LF. From genetics to genomics: ethics, policy, and parental decision-making. J Pediatr Psychol 2009;34:639-647.

21. Skinner D, Choudhury S, Sideris J, et al. Parents' decisions to screen newborns for FMR1 gene expansions in a pilot research project. Pediatrics 2011;127:e1455e1463.

22. Briss $P$, Rimer $B$, Reilley $B$, et al. Promoting informed decisions about cancer screening in communities and healthcare systems. Am J Prev Med 2004; $26: 67-80$.

23. Mullen PD, Allen JD, Glanz K, et al. Measures used in studies of informed decision making about cancer screening: a systematic review. Ann Behav Med 2006;32:188-201.
24. Bekker HL, Hewison J, Thornton JG. Understanding why decision aids work: linking process with outcome. Patient Educ Couns 2003;50:323-329.

25. O'Connor AM, Bennett CL, Stacey D, et al. Decision aids for people facing health treatment or screening decisions. Cochrane Database Syst Rev 2009:3:CD001431.

26. Volk RJ, Hawley ST, Kneuper S, et al. Trials of decision aids for prostate cancer screening: a systematic review. Am J Prev Med 2007;33:428-434.

27. Peate $M$, Meiser B, Cheah BC, et al. Making hard choices easier: a prospective, multicentre study to assess the efficacy of a fertility-related decision aid in young women with early-stage breast cancer. Br $J$ Cancer 2012;106:1053-1061.

28. Brehaut JC, Carroll K, Elwyn G, et al. Informed consent documents do not encourage good-quality decision making. J Clin Epidemio/ 2012;65:708-724.

29. Sorenson JR, Lakon C, Spinney T, Jennings-Grant T. Assessment of a decision aid to assist genetic testing research participants in the informed consent process. Genet Test 2004;8:336-346.

30. Bailey DB Jr, Lewis MA, Harris SL, et al. Design and evaluation of a decision aid for inviting parents to participate in a fragile X newborn screening pilot study. J Genet Couns 2012; e-pub ahead of print 27 June 2012.

31. Elwyn G, O'Connor A, Stacey D, et al.; International Patient Decision Aids Standards (IPDAS) Collaboration. Developing a quality criteria framework for patient decision aids: online international Delphi consensus process. BMJ 2006;333:417.

32. O'Connor AM, Wennberg JE, Legare F, et al. Toward the 'tipping point': decision aids and informed patient choice. Health Aff (Millwood) 2007;26:716-725.

33. Smith SK, Trevena L, Simpson JM, Barratt A, Nutbeam D, McCaffery KJ. A decision aid to support informed choices about bowel cancer screening among adults with low education: randomised controlled trial. BMJ 2010;341:c5370.

34. Beskow LM, Fullerton SM, Namey EE, Nelson DK, Davis AM, Wilfond BS. Recommendations for ethical approaches to genotype-driven research recruitment. Hum Genet 2012;131:1423-1431.

35. Schenker $Y$, Fernandez A, Sudore R, Schillinger D. Interventions to improve patient comprehension in informed consent for medical and surgical procedures: a systematic review. Med Decis Making 2011;31:151-173.

36. Beskow LM, Linney KN, Radtke RA, Heinzen EL, Goldstein DB. Ethical challenges in genotype-driven research recruitment. Genome Res 2010;20:705-709.

37. Albada A, van Dulmen S, Ausems MG, Bensing JM. A pre-visit website with question prompt sheet for counselees facilitates communication in the first consultation for breast cancer genetic counseling: findings from a randomized controlled trial. Genet Med 2012;14:535-542.

38. Roche MI. Moving toward NextGenetic Counseling. Genet Med 2012;doi:10.1038/gim.2012.84. 